\title{
A Novel Hybrid Renewable Energy Power System using improved PSO metaheuristic algorithm
}

\author{
Faculty of Engineering, Don Bosco University, EI Salvador, CA \\ manuel.cardona@udb.edu.sv
}

Received: $5^{\text {th }}$ October 2020, Accepted: $11^{\text {th }}$ December 2020, Published: $31^{\text {st }}$ December 2020

\begin{abstract}
The hybrid systems effectively solve the disadvantages of prior standalone systems, which could only generate considerable amounts of electricity during specific periods of the year and during specific seasons. The output of solar panels, for example, would be drastically reduced at night. Because of this, hybrid systems are effective in addressing this issue because the lack of stability in one system is fully compensated for by the stability in the other. Based on the Improved PSO algorithm, this research presents an optimised hybrid PV-wind power generating system that has been tweaked to maximise the amount of electricity generated by the system.
\end{abstract}

Keywords: HRES, Optimization, Energy, Renewable

\section{Introduction}

Energy needs have increased significantly over time, yet renewable energy sources have a few major drawbacks, including their inability to guarantee reliability and their lean nature. Our foreign exchange reserves are heavily depleted by the import of petroleum items. To address these issues, renewable energy sources are viewed as the best option available to us. Fossil fuel reserves around the planet are fast depleting, and this is obvious. Hybrid renewable energy systems (HRES) can be either grid linked or better to be in stand-alone mode due to developments in renewable energy technology and power electronics converters that are used to convert the unregulated electricity generated from renewable energy sources. Most importantly, HRES is more efficient than could be done with a single energy source because it makes the best use of the operating features of renewable electricity generating technologies. Flexible fuels, high efficiency, dependability and low emissions are only some of the topics that might be addressed. There are a slew of considerations to be made when dealing with energy production hybrid systems. We know that hybrid power generation systems are more trustworthy and less expensive than single-source power generation systems because of these two characteristics: dependability and cost. Hybrid renewable electricity systems in off-grid applications are economically possible, as proved in numerous research articles, especially in remote places.

Hybrid energy systems are those that use a variety of energy conversion methods to suit a specific energy need. As a rule, these systems use at least one renewable energy source in remote places. Hybrid energy systems are taking the place of traditional ones that use only one type of fossil fuel. As a kind of distributed generation, hybrid energy systems can also be integrated into a standard electrical grid.

\section{Literature Review}

As demand for energy continues to rise and people become more conscious of the dangers of traditional fossil fuels, the creation of renewable energy has gotten a great deal of attention in the last two decades. One of the most common types of renewable energy is wind and solar photovoltaics (PV). PV systems are easy to set up and need minimal upkeep. Currently, the global PV capacity is $397 \mathrm{GW}$, which is expected to grow to $489 \mathrm{GW}$ by 2020 and $1760 \mathrm{GW}$ by 2030. It has been estimated that wind energy's worldwide capacity will climb from the current $560 \mathrm{GW}$ installed at the end of 2017 to $800 \mathrm{GW}$ by 2020 and $2000 \mathrm{GW}$ by 2030. However, standalone hybrid systems with a high level of renewable energy penetration have lately become popular for complete pollution-free power generation, particularly in isolated loads that are not connected to the grid. Due to the unpredictability of renewable energy sources like as solar and wind, a storage unit should be included to the isolated system. While increasing the system's cost and management complexity, a storage unit also increases its 
dependability in terms of power supply. The availability of numerous energy sources and the difficulty of managing storage units intensify the problem of determining the optimal system component size.

HES with diesel generator is the most cost-effective design discovered by Upadhyay et al using Particle Swarm Optimization (PSO). PSO was found to be the most successful AI strategy for optimising HES with battery and fuel cell storage systems by Maleki et al. A tiny autonomous power system was studied by Katsigiannis et al. [11], who used Simulated Annealing (SA) and Tabu Search (TS) approaches to find the most efficient schedule. PSO was employed by Paliwal et al to examine the dependability of rurally separated HRES. Koutroulis et al used a Genetic Algorithm to optimise a desalination plant's HES, which included PV, WECS, and a diesel generator (GA). It was reported by Bahramara et al that they have conducted a literature assessment on the best way to create an isolated HRES with HOMER. The RETScreen model was used by Hove et al to conduct an economic analysis of a HES powered by PV and diesel generators. Mumbai-based researchers employed HOMER to investigate the grid-linked and isolated modes of operation of an HRES serving a residential load. HES optimization can be done using software tools and AI approaches, respectively. Because the user has to enter the dimensions of each component in order to get a result, software like HOMER, RETScreen, and HYBRID2 can only deliver results based on that input range, even though the best solution may be outside of that range.

\section{Proposed Method with Results and Analysis}

For off-grid installations, the hybrid energy system provides a more efficient, cheap, and acceptable source of electricity. In this research, a mathematical model was constructed to apply several optimization algorithms to identify the optimal size of the components of the hybrid PV-wind battery with biomass. It was first necessary to briefly discuss statistical simulation of the numerous materials that were subject to the analysis, as well as the operating strategy and implementation phases of the optimization methods. As a final step, results from the Genetic Algorithm (GA), DE, Pattern Search, and the suggested improved PSO metaheuristic algorithm were compared.

\section{Particle Swarm Optimization}

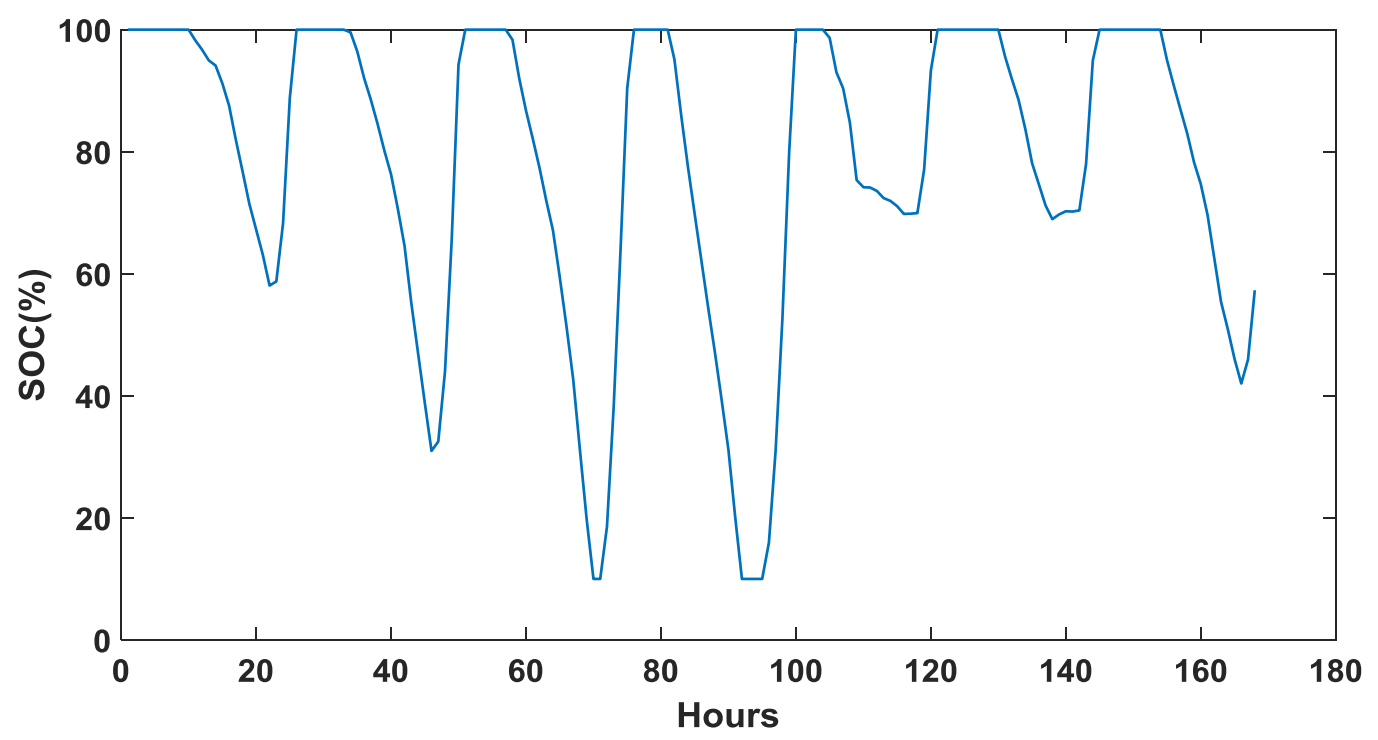

Fig 1: PSO - SOC 


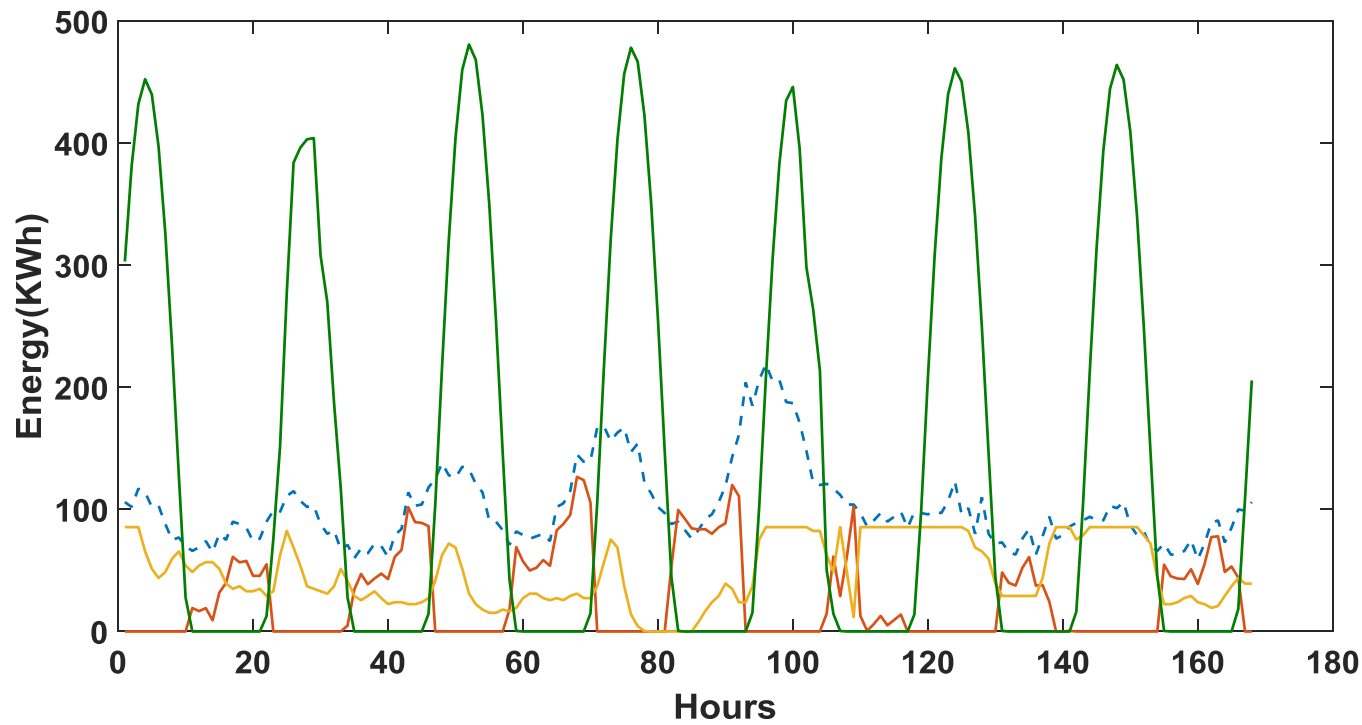

Fig 2: PSO - Energy

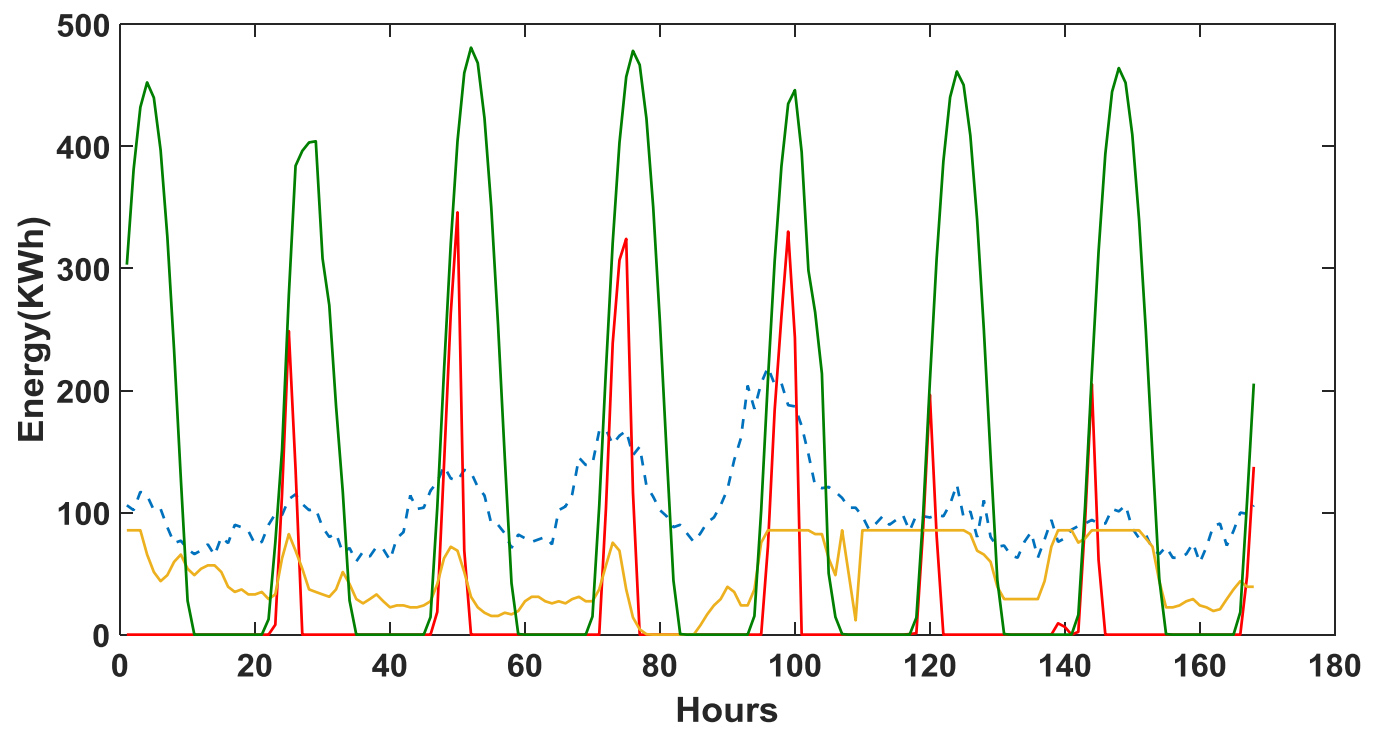

Fig 3: PSO - Energy values 


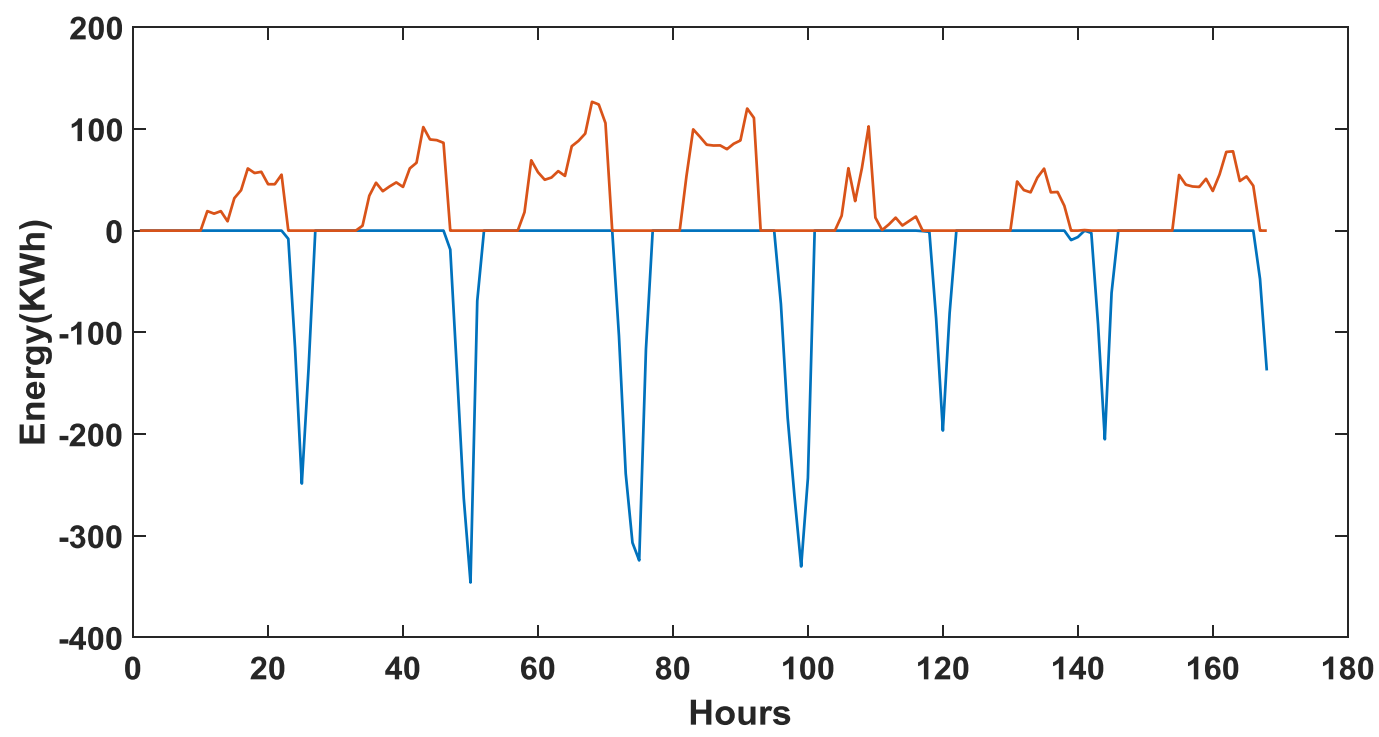

Fig 4: PSO - Energy with 2 peaks

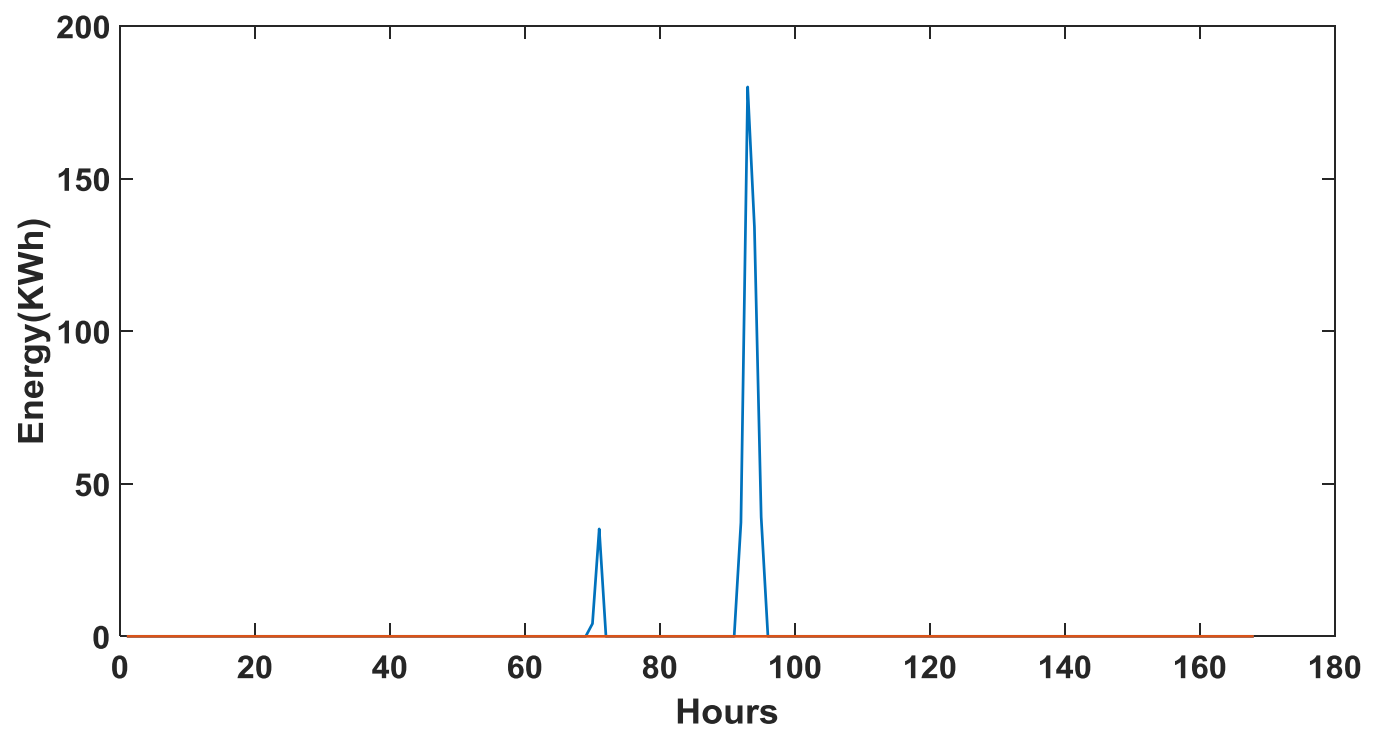

Fig 5: PSO - Energy with Peak values 


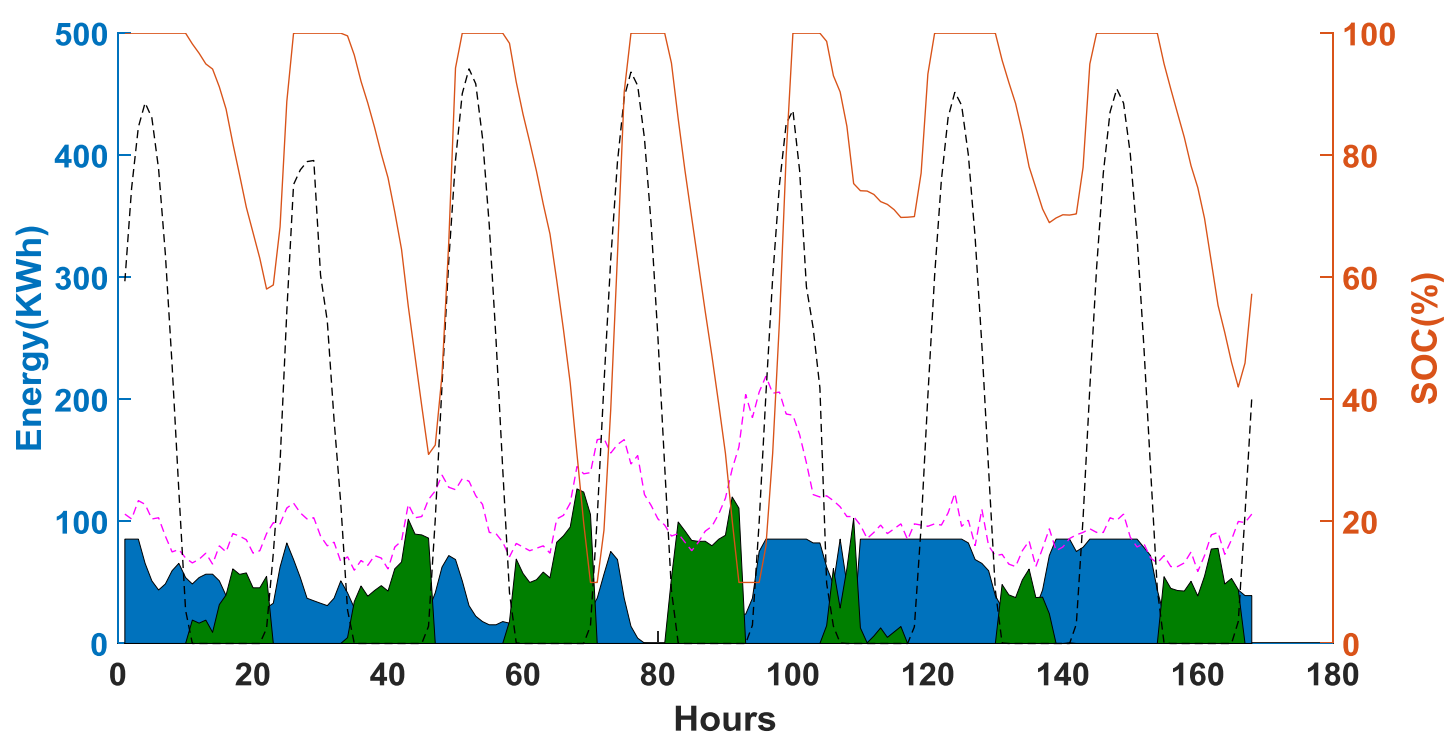

Fig 6: PSO - Energy with SOC

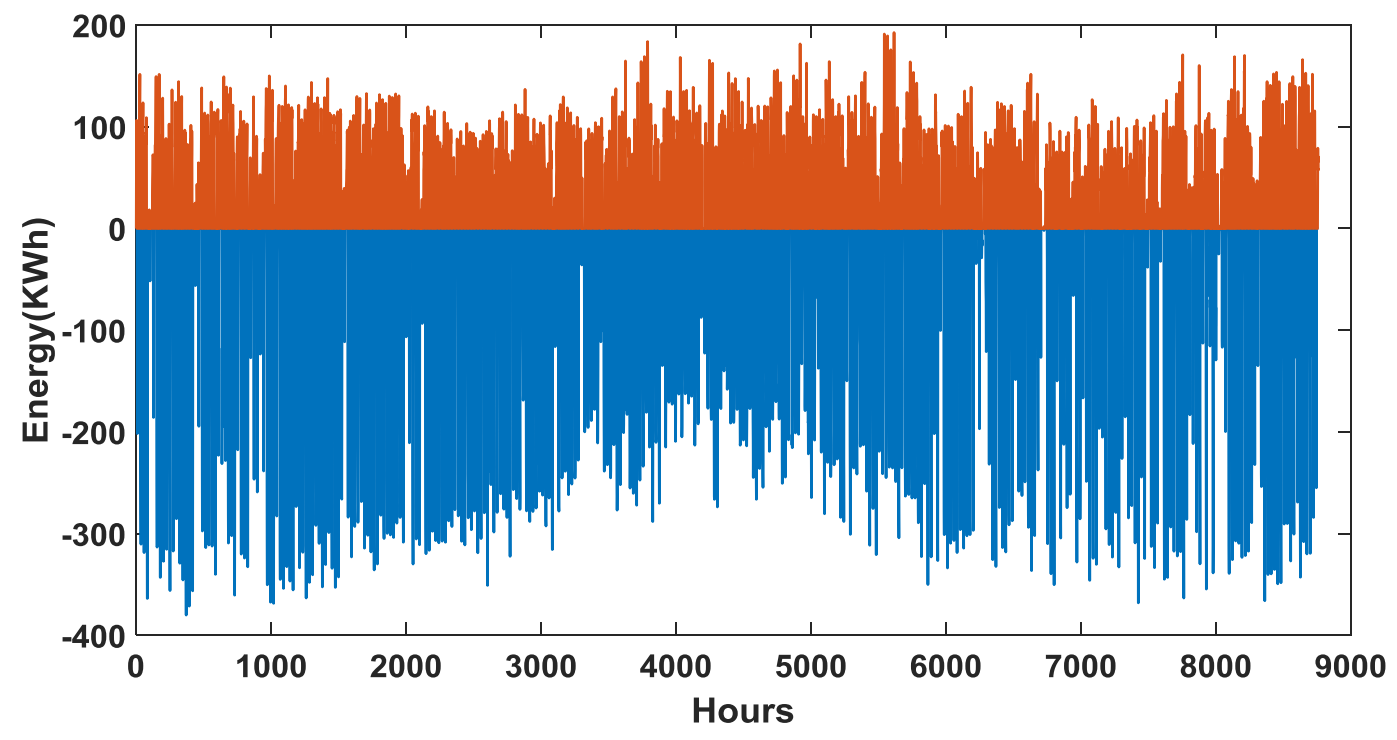

Fig 7: PSO - Energy Clusters 


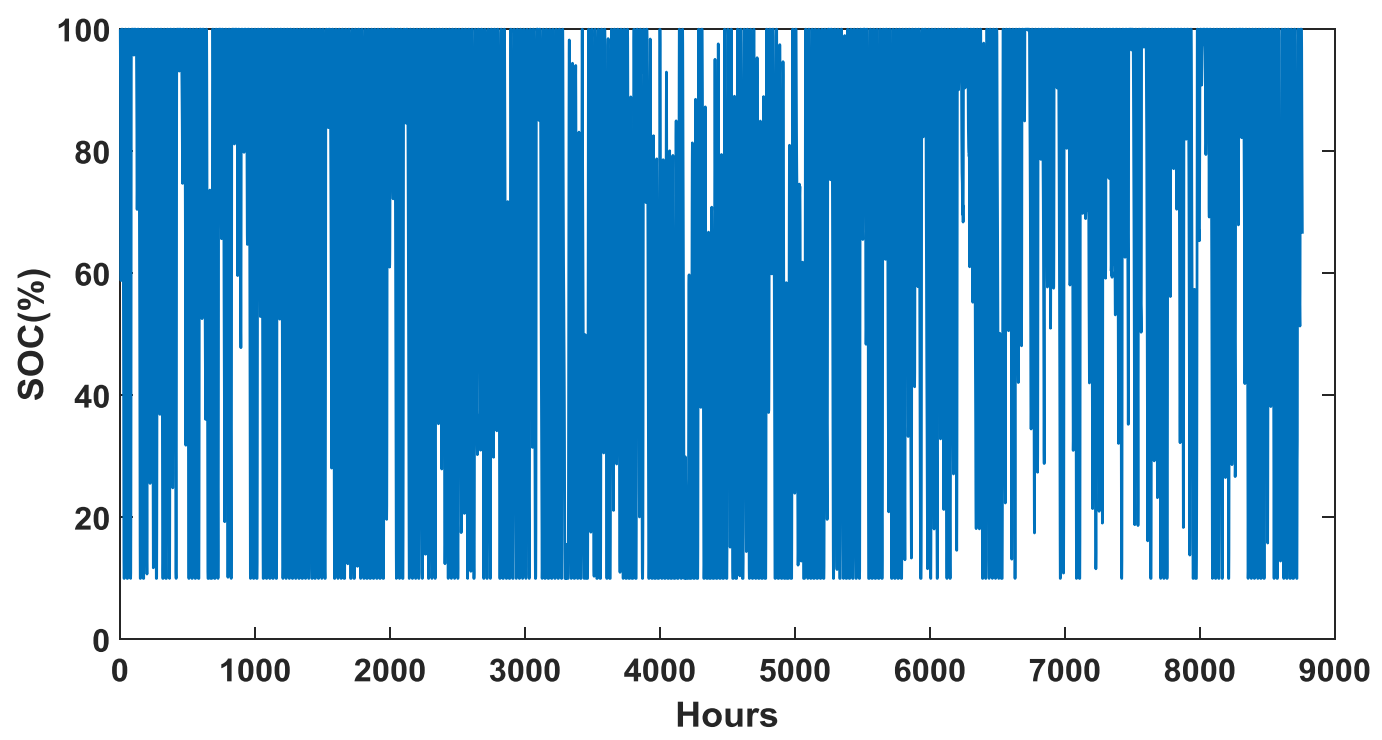

Fig 8: PSO - SOC Clusters

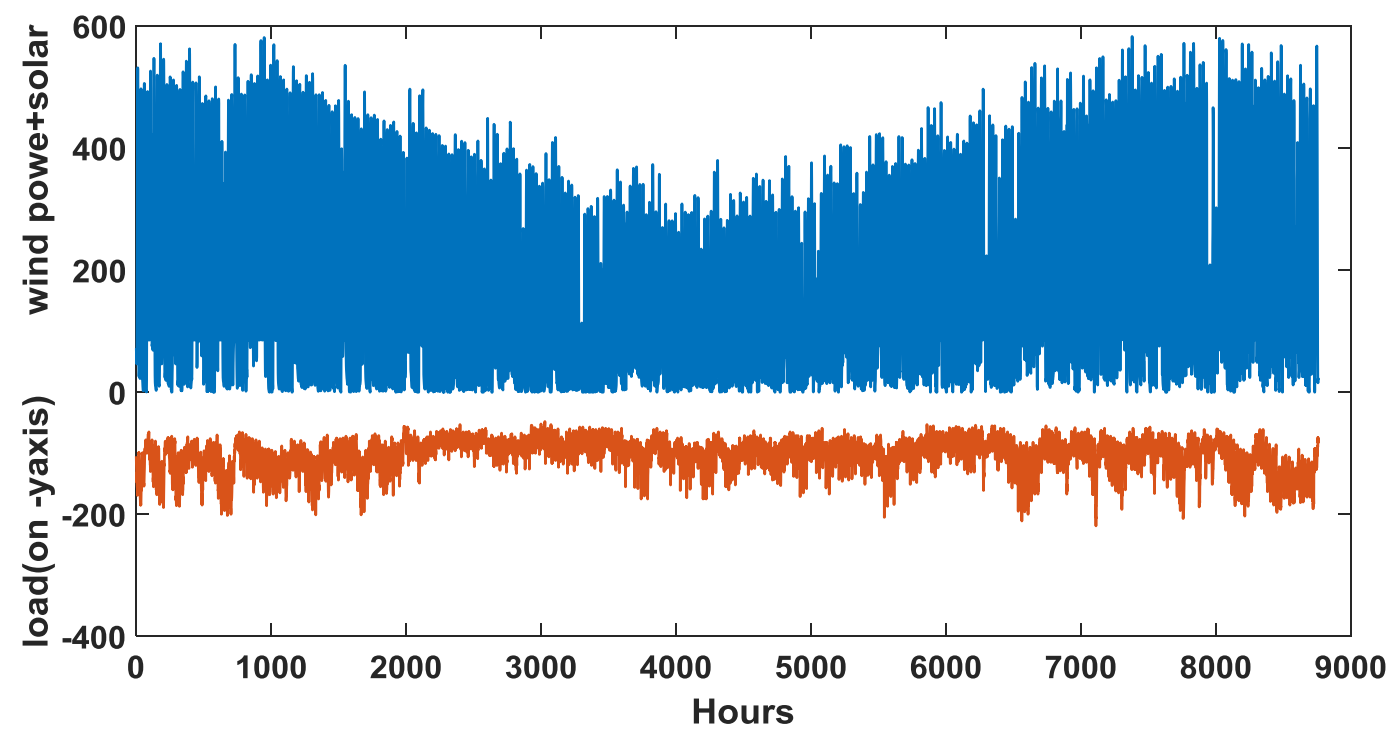

Fig 9: PSO - Wind power + Solar 


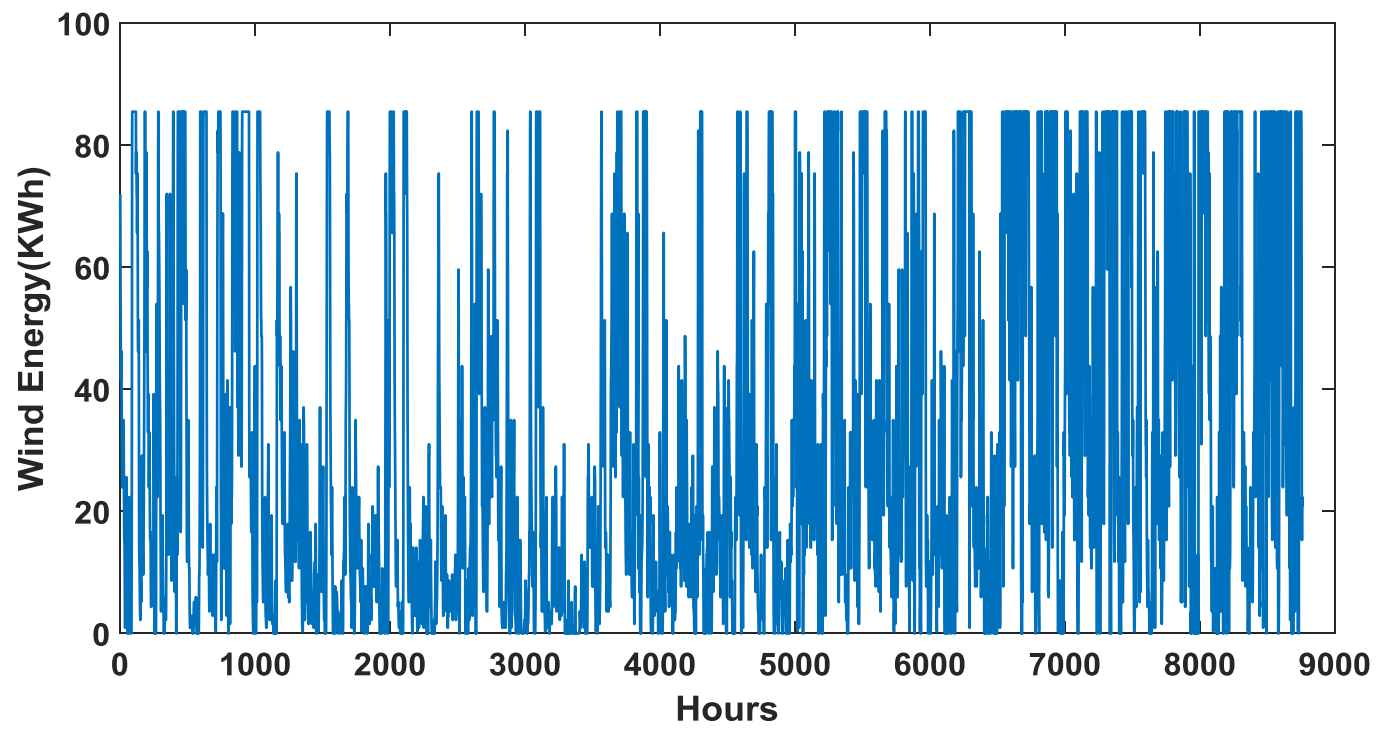

Fig 10: PSO - Wind Energy

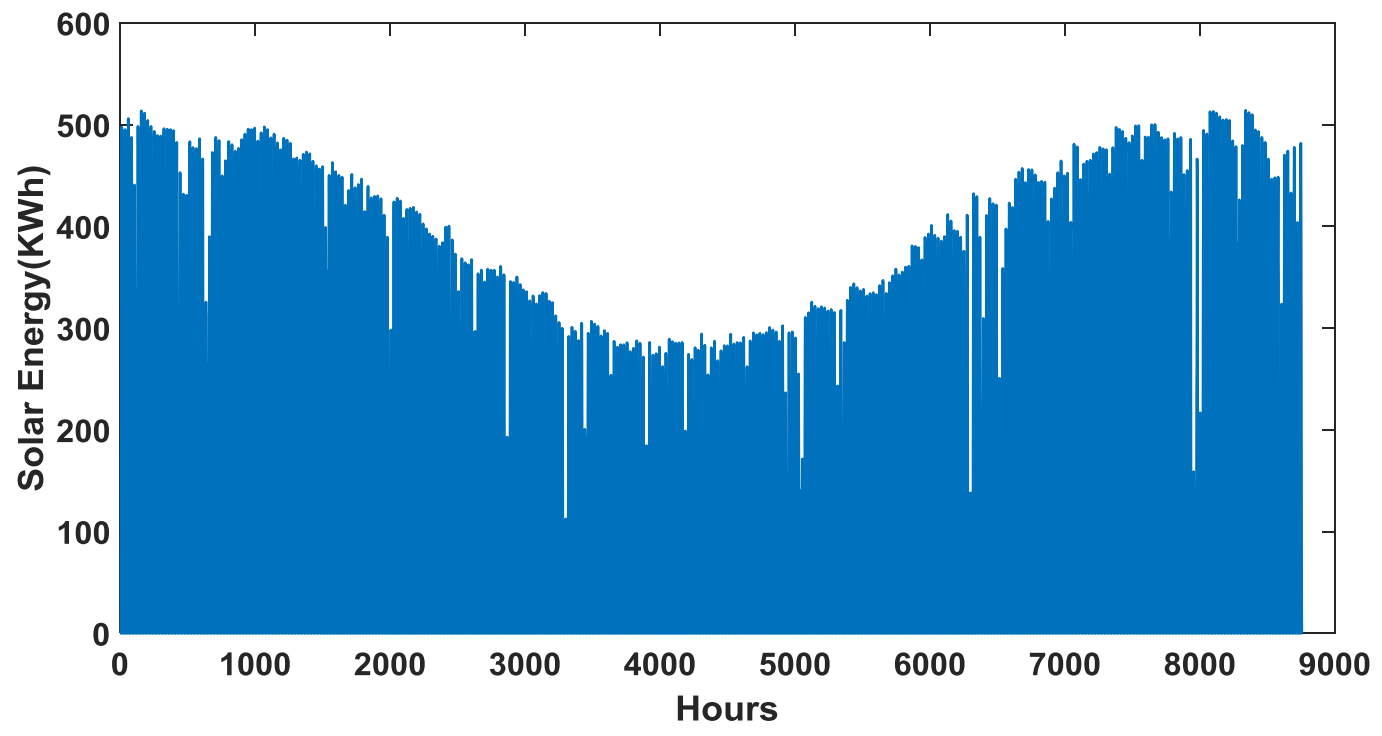

Fig 11: PSO - Solar Energy 


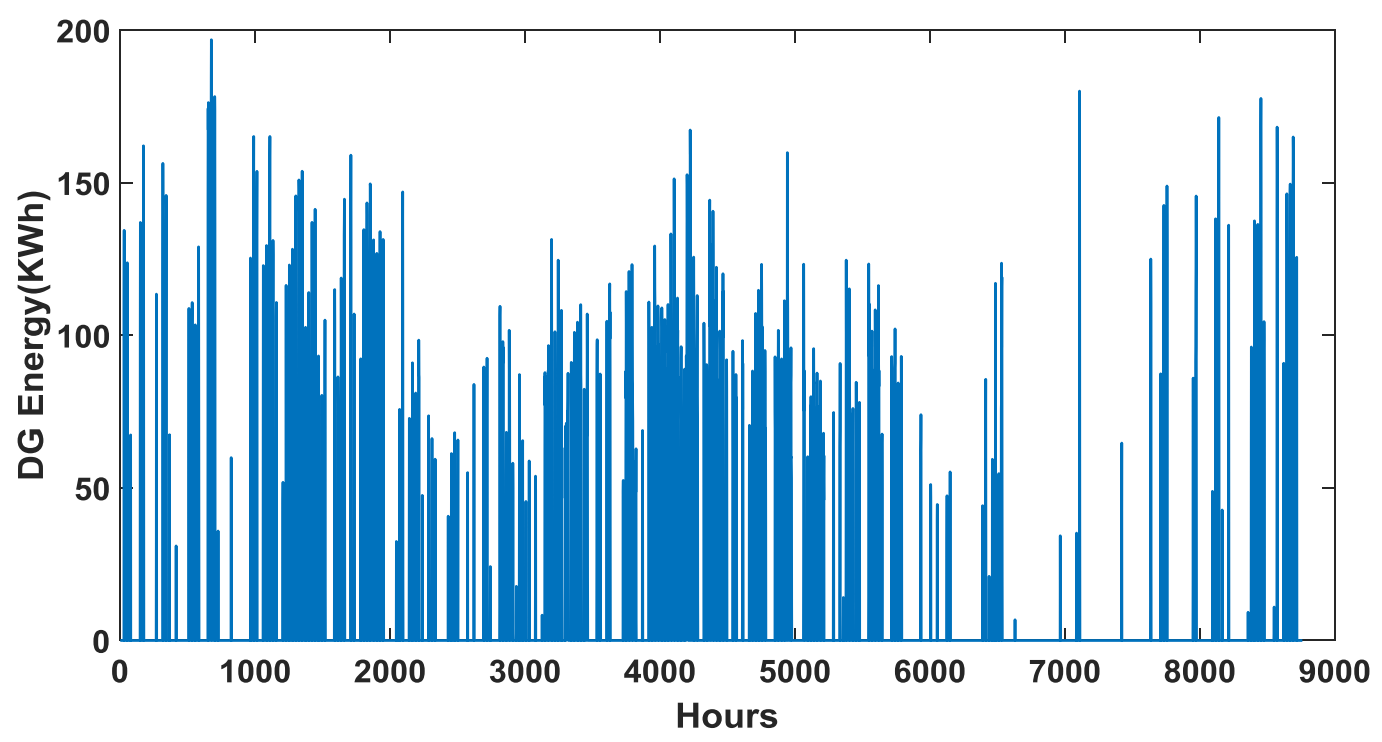

Fig 12: PSO - DG Energy

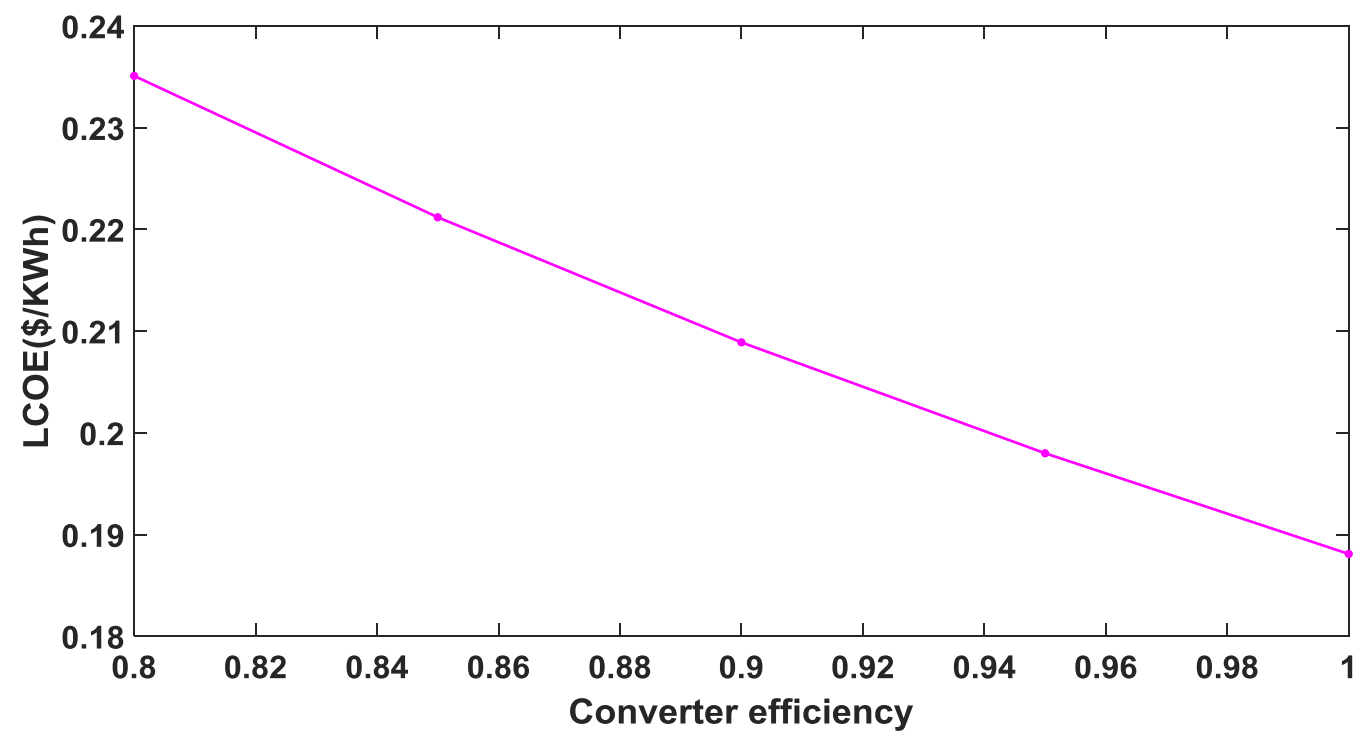

Fig 13: PSO - LCOE 


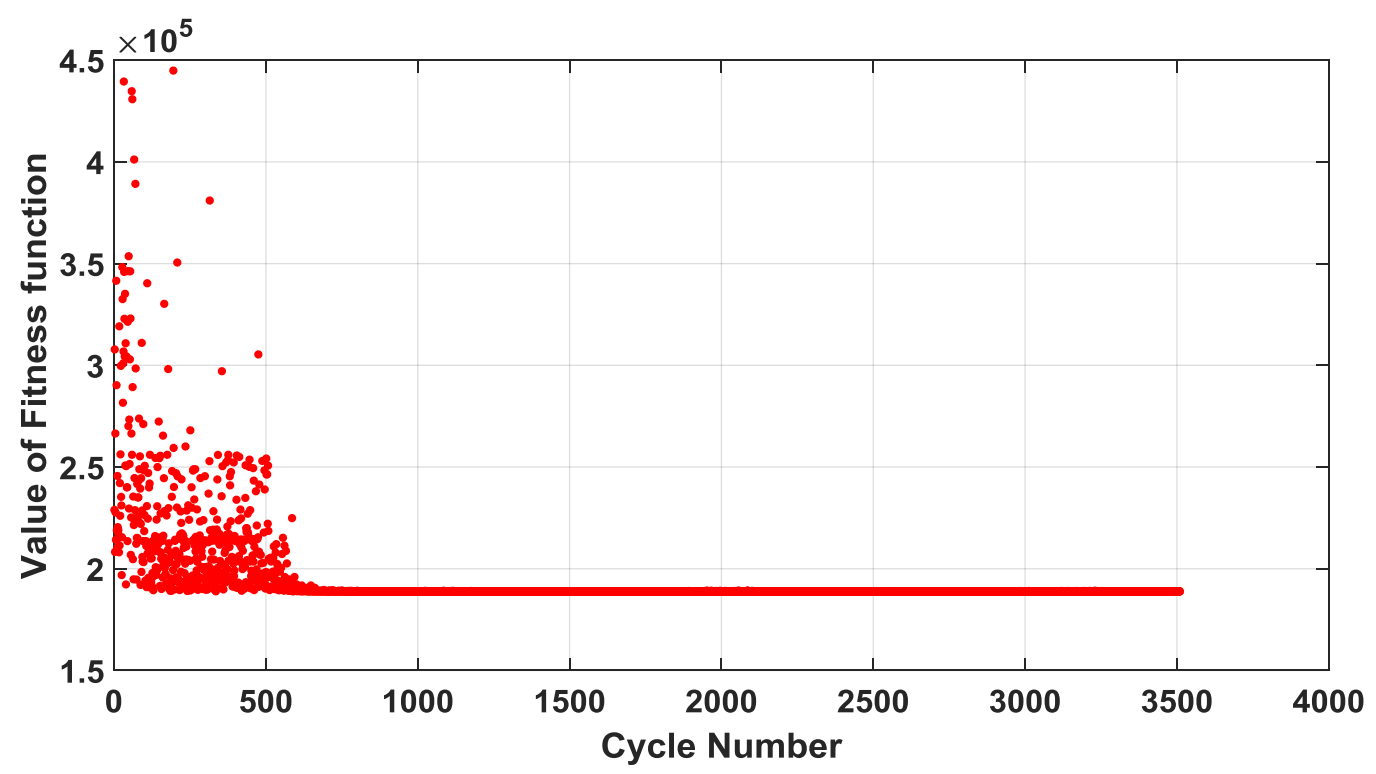

Fig 14: PSO - Value of Fitness function

Table 1: Parametric Comparison

\begin{tabular}{|c|c|c|c|c|}
\hline $\begin{array}{l}\text { Optimizatio } \\
\text { n Methods }\end{array}$ & Genetic Algorithm & $\begin{array}{l}\text { Differential } \\
\text { Evolution }\end{array}$ & Pattern Search & PSO \\
\hline \multicolumn{5}{|l|}{ Parameters } \\
\hline $\begin{array}{l}\text { Total Wind } \\
\text { energy }\end{array}$ & $\begin{array}{l}2.696236303441101 \mathrm{e} \\
+05\end{array}$ & $\begin{array}{l}2.693612464633937 \mathrm{e} \\
+05\end{array}$ & $\begin{array}{l}2.693398090325397 \mathrm{e} \\
+05\end{array}$ & $\begin{array}{l}2.693431461150991 \mathrm{e} \\
+05\end{array}$ \\
\hline $\begin{array}{l}\text { Total Solar } \\
\text { energy }\end{array}$ & $\begin{array}{l}1.053827069189736 \mathrm{e} \\
+06\end{array}$ & $\begin{array}{l}1.041569400056789 \mathrm{e} \\
+06\end{array}$ & $\begin{array}{l}1.041542723930581 \mathrm{e} \\
+06\end{array}$ & $\begin{array}{l}1.041541738153350 \mathrm{e} \\
+06\end{array}$ \\
\hline $\begin{array}{l}\text { Total DG } \\
\text { Energy } \\
\text { generation }\end{array}$ & $\begin{array}{l}7.650513912644416 \mathrm{e} \\
+04\end{array}$ & $\begin{array}{l}7.678831510447846 \mathrm{e} \\
+04\end{array}$ & $\begin{array}{l}7.678837634931551 \mathrm{e} \\
+04\end{array}$ & $\begin{array}{l}7.671290378847864 \mathrm{e} \\
+04\end{array}$ \\
\hline $\begin{array}{l}\text { Total dump } \\
\text { energy }\end{array}$ & $\begin{array}{l}4.209038270637747 \mathrm{e} \\
+05\end{array}$ & $\begin{array}{l}4.086180260602456 \mathrm{e} \\
+05\end{array}$ & $\begin{array}{l}4.085675613448485 \mathrm{e} \\
+05\end{array}$ & $\begin{array}{l}4.084771899767303 \mathrm{e} \\
+05\end{array}$ \\
\hline LCOE & 0.208089563491034 & 0.207905484630295 & 0.207904668141316 & 0.207903778408531 \\
\hline Annual cost & $\begin{array}{l}1.890089990562874 \mathrm{e} \\
+05\end{array}$ & $\begin{array}{l}1.888417991226048 \mathrm{e} \\
+05\end{array}$ & $\begin{array}{l}1.888410575007659 \mathrm{e} \\
+05\end{array}$ & $\begin{array}{l}1.888402493511388 \mathrm{e} \\
+05\end{array}$ \\
\hline Wind cost & $\begin{array}{l}3.129158882053101 \mathrm{e} \\
+04\end{array}$ & $\begin{array}{l}3.126113745208847 \mathrm{e} \\
+04\end{array}$ & $\begin{array}{l}3.125864949778407 \mathrm{e} \\
+04\end{array}$ & $\begin{array}{l}3.125903678807888 \mathrm{e} \\
+04\end{array}$ \\
\hline Solar cost & $\begin{array}{l}3.680367440501766 \mathrm{e} \\
+04\end{array}$ & $\begin{array}{l}3.637558968701893 \mathrm{e} \\
+04\end{array}$ & $\begin{array}{l}3.637465805459831 \mathrm{e} \\
+04\end{array}$ & $\begin{array}{l}3.637462362748472 \mathrm{e} \\
+04\end{array}$ \\
\hline DG1_cost & $4.022655709430182 \mathrm{e}$ & $4.020037122598376 \mathrm{e}$ & $4.020038598244276 \mathrm{e}$ & $4.016288861414650 \mathrm{e}$ \\
\hline
\end{tabular}




\begin{tabular}{|l|l|l|l|l|}
\hline & +04 & +04 & +04 & +04 \\
\hline DG2_cost & 36.062990555310854 & 36.065461311155616 & 36.065663178196516 & 36.065631754329274 \\
\hline Battery_cost & $7.459979234990088 \mathrm{e}$ & $7.491731190022182 \mathrm{e}$ & $7.491997490678180 \mathrm{e}$ & $7.495631129369365 \mathrm{e}$ \\
& +04 & +04 & +04 & +04 \\
\hline Inverter_Tc & $5.189323395980706 \mathrm{e}$ & $5.189323395980706 \mathrm{e}$ & $5.189323395980706 \mathrm{e}$ & $5.189323395980706 \mathrm{e}$ \\
ost & +03 & +03 & +03 & +03 \\
\hline Bin & $3.277622057377603 \mathrm{e}$ & $3.280217072076249 \mathrm{e}$ & $3.280341057565754 \mathrm{e}$ & $3.281254255112669 \mathrm{e}$ \\
& +05 & +05 & +05 & +05 \\
\hline Bout & $2.956465225360938 \mathrm{e}$ & $2.958807132326815 \mathrm{e}$ & $2.958918956049436 \mathrm{e}$ & $2.959741638158288 \mathrm{e}$ \\
& +05 & +05 & +05 & +05 \\
\hline
\end{tabular}

According to our tests, our algorithm outperformed the other three options. Various characteristics and qualities are used to determine the efficiency of the proposed hybrid system as stated in the tabular column 1. As an algorithm for optimising research, the enhanced Particle Swarm Optimization Technique (PSO) is utilised because it has advantages over other strategies for reducing levied energy costs (LCOE) with a suitable range of production taking into account losses between production and demand. It may be concluded from the analysis that the ideal hybrid device fulfils the load demand without breaking any rules.

\section{Conclusion}

Saving fossil fuels is the key motivation for integrating renewable energy sources. Small wind systems, solar systems, micro-hydro systems, biogas electric systems, etc. are some examples of renewable energy sources widely used in hybrid setups. Using PSO, this research proposes a method for determining the optimal system size for stand-alone hybrid PV, wind, battery, and diesel energy systems. With the aim of reducing system costs while maintaining load demand and satisfying a set of optimization requirements, the optimization team set out to find the optimal configuration. The hybrid power system is an effective, economical and adequate power source, particularly for off-grid systems. In this analysis, a mathematical model was developed to determine the optimum size of the PV-wind components with biomass through the use of different optimisation algorithms. Initially, the mathematical simulation of the different analytical materials, along with the operational method and the implementation phases of optimisation algorithms were discussed briefly. Finally the results from the Genetic Algorithm, DE, Pattern Search, were compared to the software platform results and to the proposed improved PSO metaheuristic algorithm.

\section{References}

[1.] Abbes D, Martineza A, Champenois G. Life cycle cost, embodied energy and loss of power supply probability for the optimal design of hybrid power systems. Math Comput Simul 2014;98:46-62

[2.] Abedi S, Alimardani A, Gharehpetian GB, Riahy GH, Hosseinian SH. A Comprehensive method for optimal power management and design of hybrid RES-based autonomous energy systems. Renew Sustain Energy Rev 2012;16(3):31577-87.

[3.] Aghaei J, Akbari MA, Roosta A, Gitizadeh M, Niknam T. Integrated renewable-conventional generation expansion planning using multiobjective framework. IET GenerTransmDistrib 2012;6(8):773-84.

[4.] Alsayed M, Cacciato M, Scarcella G, Scelba G. Multicriteria optimal sizing of photovoltaic-wind turbine grid connected systems. IEEE Trans Energy Convers 2013;28(2):370-9.

[5.] Arnette A, Zobel CW. An optimization model for regional renewable energy development. Renew Sustain Energy Rev 2012;16:4606-15

[6.] Atefeh BehzadiForough, RaminRoshandel. Multi objective receding horizon optimization for optimal scheduling of hybrid renewable energy system. Energy and Buildings, 2017;150: 583-597 
[7.] Brekken TKA, Yokochi A, Jouanne AV, Yen ZZ, Hapke HM, Halamay DA. Optimal energy storage sizing and control for wind power applications. IEEE Trans Sustain Energy 2011;2(1):69-77

[8.] Diaf S, Belhamel M, Haddadi M, Louche A. Technical and economical assessment of hybrid photovoltaic/wind system with battery storage in Corsica island. Energy Policy 2008;36:743-54

[9.] Dufo-López R, Bernal-Agustín JL. Multi-objective design of PV-wind-diesel-hydrogen-battery systems. Renew Energy 2008;33(12):2559-72

[10.] Ippolitoa MG, Di Silvestre ML, Sanseverino ER, Zizzo G, Graditi G. Multi-objective optimized management of electrical energy storage systems in an islanded network with renewable energy sources under different design scenarios. Energy 2014;64:648-62

[11.] Katsigiannis YA, Georgilakis PS, Karapaidakis ES. Hybrid simulated annealing-tabu search method for optimal sizing of autonomous power systems with renewables. IEEE Trans Sustain Energy 2012;3(3):330-8.

[12.] Katsigiannis YA, Georgilakis PS, Karapidakis ES. Multiobjective genetic algorithm solution to the optimum economic and environmental performance problem of small autonomous hybrid power systems with renewables. IET Renew Power Gener 2010;4(5):404-19.

[13.] Maheri A. Multi-objective design optimization of standalone hybrid wind-PV-diesel systems under uncertainties. Renew Energy 2014;66:650-61

[14.] Moura PS, DeAlmeida AT. Multi-objective optimization of a mixed renewable system with demand-side management. Renew Sustain Energy Rev 2010;14(5):1461-8Nasiraghdam H, Jadid S. Optimal hybrid PV/WT/FC sizing and distribution system reconfiguration using multiobjective artificial bee colony (MOABC) algorithm. Sol Energy 2012;86(1):3057-71.

[15.] Ould B, Sambou V, Ndiaye PA, Kébé CMF, Ndongo M. Optimal design of a hybrid solarwind-battery system using the minimization of the annualized cost system and the minimization of the loss of power supply probability (LPSP). Renew Energy 2010;35(10):2388-90

[16.] Sharafi M, ELMekkawy TY. Multi-objective optimal design of hybrid renewable energy systems using PSO-simulation based approach. Renew Energy 2014;68:67-79

[17.] Tant J, Geth F, Six D, Tant P, Driesen J. Multiobjective battery storage to improve PV integration in residential distribution grids. IEEE Trans Sustain Energy 2013;4:182-91

[18.] Wang L, Singh C. Multicriteria design of hybrid power generation systems based on a modified practice swarm optimization algorithm. IEEE Trans Energy Convers 2009;24(1):163-72 